\title{
Preparation of Poly(vinyl chloride) Latexes Using a Dual Surfactant System: The Effect in the Particle Size Distribution
}

\author{
A. Tomás, ${ }^{1}$ M. H. Gil, ${ }^{2}$ J. C. Bordado, ${ }^{3}$ P. Gonçalves, ${ }^{1}$ P. Rodrigues ${ }^{1}$ \\ ${ }^{1}$ Companhia Industrial de Resinas Sintéticas, CIRES, S.A., Development Department, Avanca-Estarreja, Portugal \\ ${ }^{2}$ Chemical Engineering Department, Coimbra University, Coimbra, Portugal \\ ${ }^{3}$ Chemical and Biological Engineering Department, Instituto Superior Técnico, Lisboa, Portugal
}

Received 31 May 2008; accepted 10 October 2008

DOI 10.1002/app.29509

Published online 5 February 2009 in Wiley InterScience (www.interscience.wiley.com).

\begin{abstract}
The control of the average particle size and size distribution in the emulsion polymerization of vinyl chloride monomer is an important parameter to determine, not only the latex characteristics, but also the properties of the final dispersion powder in several industrial applications. It is possible to manipulate the particle size distribution (PSD) by applying a mixture of an anionic surfactantfatty alcohol before the start of the free radical polymerization. Contrary to the procedures of the miniemulsion and
\end{abstract}

the derivative diffusional swelling techniques, no kind of high shear is applied to the monomer and/or surfactant mixtures. In fact, the concentration and selection of the anionic surfactant, together with the fatty-alcohol, can play an interesting role on the final PSD of the polymer's particles. ○ 2009 Wiley Periodicals, Inc. J Appl Polym Sci 112: 1416-1424, 2009

Key words: miniemulsion; diffusional swelling; VCM; particle size distribution; fatty alcohol

\section{INTRODUCTION}

The control of the average particle size and size distribution during the emulsion polymerization of vinyl chloride monomer (VCM) has been studied for decades, since they represent an important parameter for the definition of the rheological behavior of the polymer dispersion into the liquid plasticizer, in the so called paste or plastisol's process. ${ }^{1}$

In the conventional emulsion polymerization, an ionic surfactant, an inorganic initiator and the vinyl monomer are dispersed in a water phase to produce a monomodal particle size distribution (PSD) in the submicron range. ${ }^{2}$ Adding this, the utilization of a seeding technique from the start of polymerization allows the production of higher particle sizes and even multimodal distributions. ${ }^{3,4}$ The distribution of the different class sizes at the end of polymerization will define mostly the flow type of the final plastisol. Thus, for an optimum packing, the broadening of the distribution will contribute for a low viscosity level, since more liquid plasticizer will be available. This effect is normally applied to decrease the plasti-

Correspondence to: A. Tomás (arnaldo.tomas@cires.pt).

Contract grant sponsor: FCT; contract grant number: SFRH/BDE/15534/2005.

Journal of Applied Polymer Science, Vol. 112, 1416-1424 (2009) (c) 2009 Wiley Periodicals, Inc. cizer dosage or to improve the application process of the plastisol. ${ }^{5}$

It has long been known, from the pioneer work of Ugelstad and coworkers, ${ }^{6-8}$ that the addition of long-chain fatty alcohols increases the dispersion capacity of anionic surfactants. With a mixed system of sodium lauryl sulfate (SLS) and cetyl alcohol (CA), Ugelstad et al. ${ }^{6}$ reported that the polystyrene polymer particles at the end of the polymerization had a similar size of the starting monomer droplets. This discovery gave rise to a new technique where the micellar and homogeneous particle nucleation could be replaced by the nucleation in the monomer droplets. Following these early publications, soon the term Miniemulsion was applied for the case, where the liquid monomer droplets are stabilized against molecular diffusion (mechanism 1) and coalescence (mechanism 2) from the beginning of the polymerization. ${ }^{3}$

From the work of Higuchi and Misra, ${ }^{9}$ it was possible to conclude that if the small droplets are not stabilized against diffusional degradation (Ostwald ripening), they will disappear with the observed increase on the average droplet size. Therefore, mechanism 1 is normally prevented by adding a small quantity of a highly monomer-soluble and water-insoluble agent (hydrophobe), referred as cosurfactant or coemulsifier.

The effects of the second mechanism are suppressed as much as possible, by adding an 


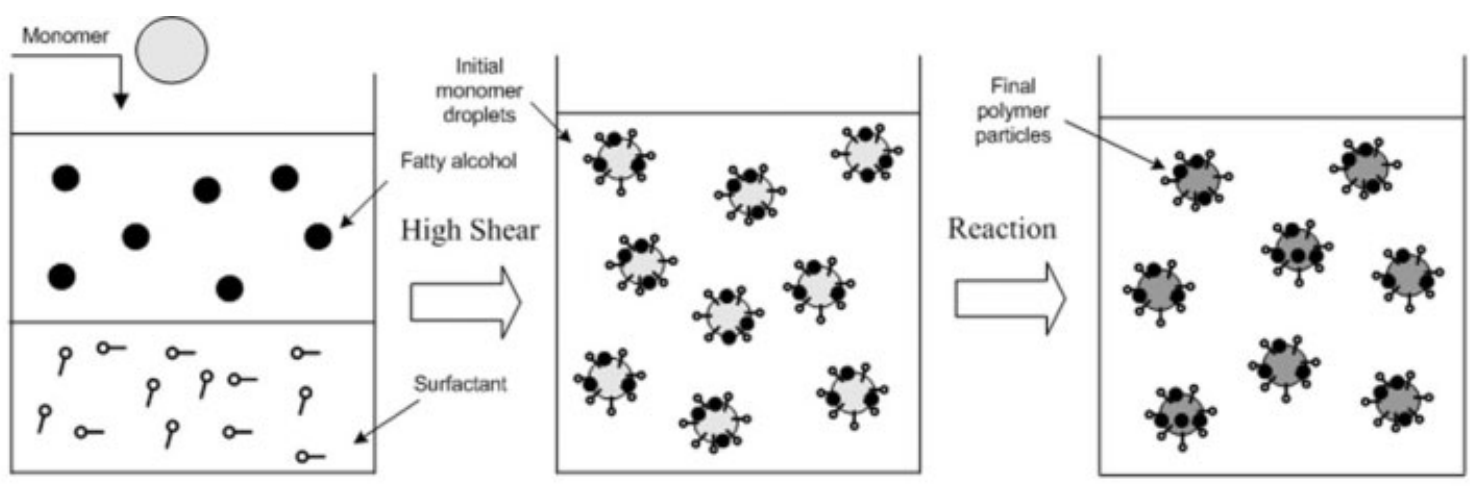

a)

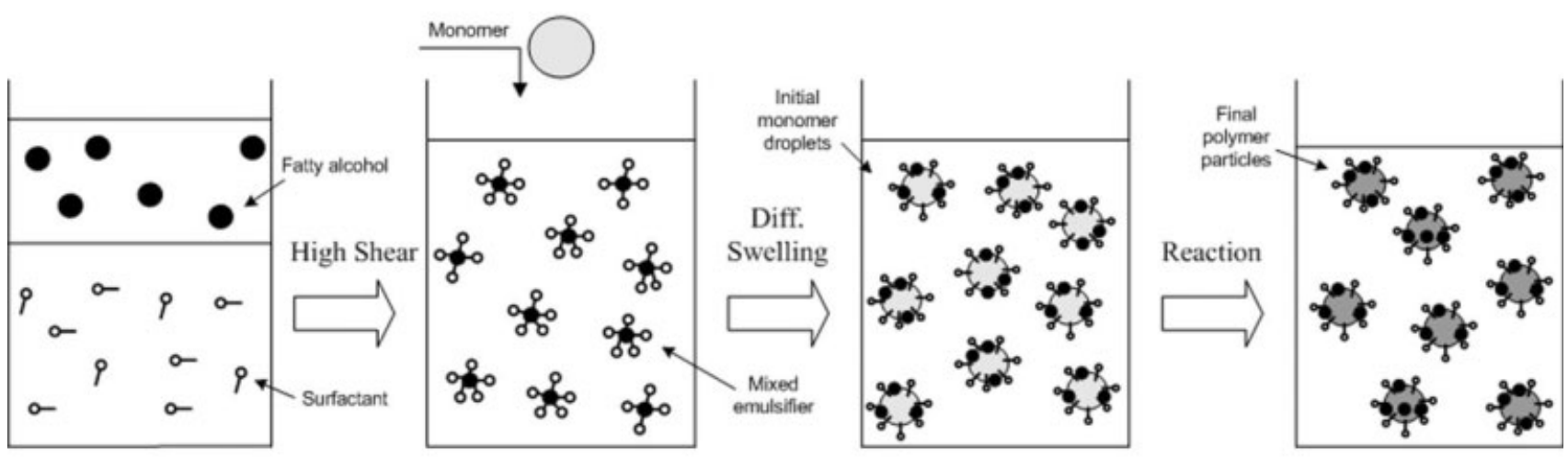

b)

Figure 1 Procedures for: (a) miniemulsion followed by polymerization; (b) diffusional swelling followed by polymerization.

appropriate surfactant (emulsifier), assuring that the droplets do not aggregate by collision and coalescence. $^{3}$

The process of miniemulsion follows general rules where the selected monomer, surfactant and cosurfactant are normally subjected to a previous homogenization step with a variable shear applied by mechanical or ultrasound devices. However, for the case of vinyl chloride, this procedure is very complicated by the fact that the monomer is gaseous at normal pressures, requiring special precautions due to his high flammable and toxic nature.

To overcome that problem, Ugelstad et al. ${ }^{10,11}$ reported a new procedure where the monomer was added to a previous mixed emulsifier system, consisting of a long fatty alcohol and an ionic emulsifier. This so called the Diffusional Swelling method, involved, in a first step, an intense homogenization of an aqueous mixture of a high insoluble compound ( $Y$ compound) and an emulsifier. After this, a new compound ( $Z$ compound), which has higher water solubility, was added to the said pre-emulsion to diffuse through the water into the $\mathrm{Y}$ droplets. When applying this procedure to the emulsion poly- merization, the $\mathrm{Z}$ compound normally matches to the vinyl monomer. ${ }^{11}$

Figure 1(a,b) illustrates the differences between the standard miniemulsion and the diffusional swelling methods.

Although both methods have a wide range of applications, the homogenization conditions, as well the type and concentration of the selected compounds were found to be fundamental on the dispersion stability and final properties of the emulsion polymers. 2,10

Because of the high water solubility of the monomer and the strongly exothermic free radical reaction, a semicontinuous reactor operation is often applied to have a tight control over all the process parameters, $^{12}$ namely, the surfactant concentration, over the particle size evolution, followed by the dosage of monomer and initiator over the conversion rate. For example, the application of several reaction steps, with a starting mixture of water, emulsifier and initiator to which some portion of monomer is added. After this so called nucleation step, others steps can be made, charging more monomer, water or other ingredients over the pre-establish feed strategy of the polymerization recipe. ${ }^{13}$ 


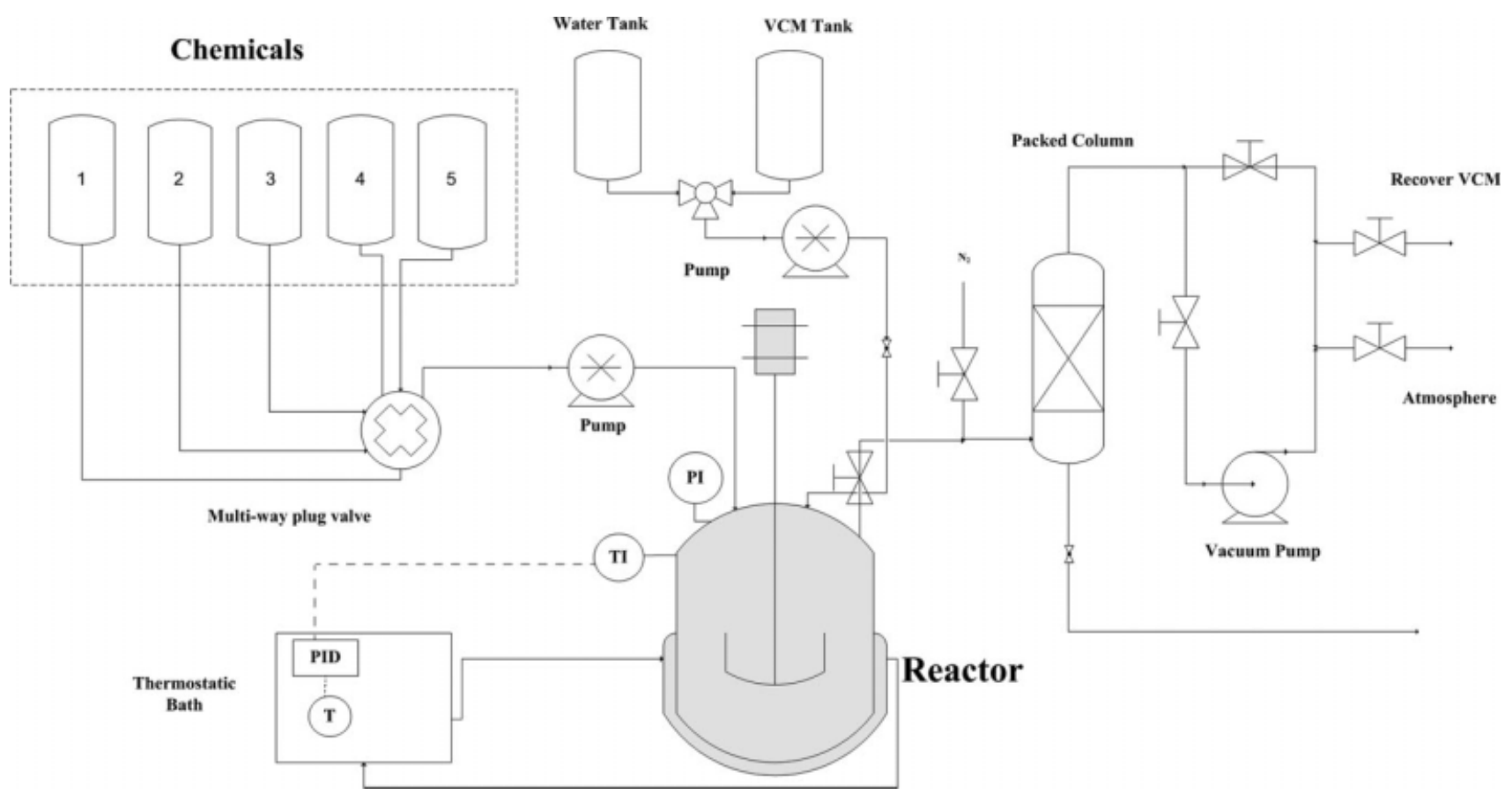

Figure 2 Scheme of the pilot plant.

Following the coemulsifier technique, the aim of this article is to examine the effect of applying a previous mixture of a surfactant and a fatty alcohol before the first nucleation step correlating with the final polymer's particle size and size distribution. Nevertheless, the homogenization step, normally applied to achieve a higher number of small monomer droplets, was substituted by a mild stirring of the surfactant and cosurfactant at a convenient temperature.

Adding that, by changing the concentration and type of the surfactant, the micellar nucleation can be strongly affected with the correspondent differences at the end of the emulsion polymerization.

\section{EXPERIMENTAL}

\section{Materials}

For the production of the emulsion polymer samples, VCM, from Shin Etsu B.V. [purity 99.99\% (w/ $w)$ from chromatographic method] was used with deionized water (conductivity $<10 \mu \mathrm{s} \mathrm{m}^{-1}$ ) (industrial utility). As main surfactant, ammonium laurate $(\mathrm{AL})$, produced from the neutralization of lauric acid (min. 99\% $\mathrm{C}_{12}$ purity) and ammonia solution $(20 \%$ $w / w)$ (commercial grades) and as a free radical initiator, ammonium persulfate (purity 99\% $w / w$ ) (commercial grade) from Brenntag S.A. As others studied surfactants, commercial grades of SLS, sodium octyl sulfate (SOS) and CA (min. 95\% $\mathrm{C}_{16}$ purity) from Cognis Iberia S.A.
The critical micellar concentration of all anionic emulsifiers was determined according to the method Wilhelmy-Plate at $298.15 \mathrm{~K}\left(25^{\circ} \mathrm{C}\right)$.

\section{Procedure}

The polymerizations reactions were carried in a pilot plant equipped with a $5 \mathrm{~L}$ reactor (designed by CIRES, S.A.). Figure 2 shows a scheme of the pilot plant installation, with several tanks and dosing pumps for the dosage of surfactants, water and monomer into the reactor. The reacting mixture was stirred with an anchor agitator, which was connected to a variable speed motor. The emulsion temperature was measured by a thermocouple installed inside the reactor, whose outlet signal was directly connected to a PID temperature controller of an external water bath that, through a closed circuit into the reactor jacket, controls the reaction temperature.

After the initial charge with deionized water, the (mixed) emulsifier system and the initiator (solid) were charged, the reactor was closed and the mixture heated to $318.15 \mathrm{~K}\left(45^{\circ} \mathrm{C}\right)$. At this temperature, vacuum was applied to remove oxygen that, otherwise, would affect the reaction kinetics. ${ }^{14}$ After the vacuum operation, the reaction temperature $\left(T_{\text {poly }}\right)$ set-point was set to $324.65 \mathrm{~K}\left(51.5^{\circ} \mathrm{C}\right)$ and the designated quantity of VCM for the first step was charged with a reciprocating pump. When it was detected a $0.5 \times 10^{5} \mathrm{~Pa}$ G difference between the reactor's pressure and the correspondent saturation pressure of VCM (at $324.65 \mathrm{~K}$ ), a new step was initiated with a 
TABLE I

Polymerization Recipe (Three Steps)

\begin{tabular}{lc}
$T_{\text {poly }}: 51.5^{\circ} \mathrm{C}$ & $200 \mathrm{rpm}$ \\
Initial charge & Mass, $\mathrm{g}$ \\
Water & 1650 \\
$\left(\mathrm{NH}_{4}\right)_{2} \mathrm{~S}_{2} \mathrm{O}_{8}$ & 3.2 \\
Surfactant & Variable \\
Coemulsifier & Variable \\
Premix (yes/no) & - \\
Step 1 & \\
VCM & 366 \\
Step 2 & \\
VCM & 366 \\
Surfactant & 4.0 \\
Step 3 & \\
VCM & 366 \\
Surfactant & 4.6 \\
\hline
\end{tabular}

subsequent charge of more surfactant and monomer. At the end of the last reaction step, as soon as the same pressure drop was detected, the unconverted VCM was quickly recovered through a column until the reactor pressure reached the atmosphere condition. Then, the reactor was purged with nitrogen and the latex was discharged for sampling and analysis.

\section{Recipe}

Table I indicates the standard recipe for the emulsion polymerization of VCM. The semibatch operation involves an initial charge procedure of water, surfactant and initiator, followed by the reaction steps with multiple additions of monomer and surfactant. The important variables are the amount of emulsifier and coemulsifier at the initial charge and whether they were premixed before being charged. To have the same conversion yield, the already referred pressure drop was kept the same in each step in all made batches.

In the case of a premix procedure, the emulsifier solution $(5 \% w / w)$ was heated to $324.15 \mathrm{~K}\left(51^{\circ} \mathrm{C}\right)$ and the melted coemulsifier (CA) at the same temperature, was slowly added to it. The agitation was guaranteed by a simple magnetic bar running at low speed. Before being introduced in the reactor, the initiator $\left(\left(\mathrm{NH}_{4}\right)_{2} \cdot \mathrm{S}_{2} \mathrm{O}_{8}\right)$ was also introduced in the aqueous and homogenous mixture.

\section{Particle size distribution}

Laser diffraction spectroscopy (LDS): MastersizerHydro 2000S, Malvern Instruments, UK, was used for PSD measurement.

Before the analysis, a calibration run was made with a known PSD sample to set the operation and data range of the equipment and software. Also, to improve the analysis conditions, the latex samples were previously diluted with water and added a small portion of a selected surfactant and ammonia. All LDS analyses were repeated twice for the same sample.

LDS parameters:

$d_{50}$-Median of the particle size distribution, $\mathrm{nm}$

$d_{10}$-Particle diameter corresponding to the $10 \%$ cumulative percentage, $\mathrm{nm}$

$d_{90}$-Particle diameter corresponding to the $90 \%$ cumulative percentage, $\mathrm{nm}$

$\left(d_{90}-d_{10}\right) /$ day $_{50}$-Distribution span (measurement of the PSD width)

$d_{3,2}$ - Surface area mean diameter $(\mathrm{nm})$

From the definition of $d_{3,2}$ :

$$
d_{3,2}=\frac{\sum_{i} n_{i} \cdot d_{i}^{3}}{\sum_{i} n_{i} \cdot d_{i}^{2}} \quad(\mathrm{~nm})
$$

where $d_{i}$ is the diameter of individual particles, $n_{i}$ the number of particles with diameter $d_{i}$. The $d_{3,2}$ parameter, from the LDS analysis, corresponds to a diameter of a spherical particle having the same ratio of volume to surface area as in the entire distribution.

The surface area of the particles per kilogram of polymer was calculated from:

$$
\begin{aligned}
A_{s}= & \frac{\pi \cdot \sum_{i} n_{i} \cdot d_{i}^{2}}{\rho_{p} \cdot \frac{4}{3} \cdot \pi \cdot \frac{1}{8} \cdot \sum_{i} n_{i} \cdot d_{i}^{3}} \\
& =\frac{\sum_{i} n_{i} \cdot d_{i}^{2}}{\rho_{p} \cdot \frac{1}{6} \sum_{i} n_{i} \cdot d_{i}^{3}} \quad\left(\mathrm{~m}^{2} \cdot \mathrm{kg}^{-1} \text { of polymer }\right)
\end{aligned}
$$

Considering, the PVC density $\left(\rho_{p}\right)$ equal to $1.393 \times$ $10^{3} \mathrm{~kg} \mathrm{~m}^{-3}\left(20^{\circ} \mathrm{C}\right)^{15}$ and Eq. (1):

$$
A_{s}=\frac{4.31 \times 10^{-3}}{d_{3,2} .1 \times 10^{-6}} \quad\left(\mathrm{~m}^{2} \cdot \mathrm{g}^{-1} \text { of polymer }\right)
$$

The average number of particles $\left(N_{p}\right)$ per mass of polymer can be estimated from $A_{s}$ and $d_{3,2}$, since:

$N_{p}=\frac{A_{s}}{\pi \cdot\left(d_{3,2} .1 \times 10^{-6}\right)^{2}}=\frac{4.31 \times 10^{-3}}{\pi \cdot\left(d_{3,2} .1 \times 10^{-6}\right)^{3}}$

(Number of particles per gram of polymer)

\section{Transmission electron microscopy}

The poly(vinyl chloride) latexes were diluted with deionized water until the proper concentration was obtained. A sample of the obtained diluted latex was sprayed directly to a transmission electron 
TABLE II

Initial Batches Strategy with Different Coemulsifier Dosages

\begin{tabular}{|c|c|c|c|c|c|c|c|c|}
\hline & Unit $\backslash$ Batch & B1 & B2 & B3 & B4 & B5 & B6 & B7 \\
\hline $\mathrm{VCM}_{\mathrm{t}}$ & $\mathrm{g}$ & 1100 & 1100 & 1100 & 1100 & 1100 & 1100 & 1100 \\
\hline No. steps & - & 3 & 3 & 3 & 3 & 3 & 3 & 3 \\
\hline CA (Step 1) & $\mathrm{g}$ & - & 2.24 & 2.24 & 6.73 & 11.22 & 17.95 & 22.44 \\
\hline CA:AL & - & & 1 & 1 & 3 & 5 & 8 & 10 \\
\hline Premix & - & - & No & Yes & Yes & Yes & Yes & Yes \\
\hline$d_{3,2}$ & $\mathrm{~nm}$ & 236 & 292 & 298 & 311 & 315 & 421 & 588 \\
\hline$\left(d_{90}-d_{10}\right) / d_{50}$ & - & 0.590 & 0.590 & 0.583 & 1.858 & 1.784 & 1.055 & 0.409 \\
\hline PSD & - & Monomodal & Monomodal & Bimodal & Bimodal & Bimodal & Bimodal & Monomodal \\
\hline$N_{p} \times 10^{6}$ & $N_{p} \mathrm{~g}^{-1}$ & 104 & 55 & 51 & 45 & 43 & 18 & 6 \\
\hline$A_{s}$ & $\mathrm{~m}^{2} \mathrm{~g}^{-1}$ & 18.3 & 14.8 & 14.5 & 13.8 & 13.7 & 10.2 & 7.3 \\
\hline
\end{tabular}

microscopy (TEM) grid to get a uniform film. The grid was examined by using an electron microscope JEOL JEM-100S, and the TEM images were acquired with an installed camera.

\section{RESULTS AND DISCUSSION}

\section{Effect of the coemulsifier and premix procedure}

To establish a first comparison basis, seven batches were conducted with a progressive increase of the coemulsifier (CA), keeping the same dosage of AL (Table II). The recipe adopted, from Table I, consists of three reaction steps with an overall quantity of VCM of $1100 \mathrm{~g}$. Also, for the first batches B1 and B2, there was no kind of premixture of the emulsifiers before entering the reactor. Nevertheless, for B3-B7, CA was previously mixed with the anionic surfactant according to the stated procedure, as well as the initial water was charged at the same temperature.

Regarding batch B1, the coemulsifier CA was not added to know the PSD from a conventional emulsion polymerization with a predominant micellar

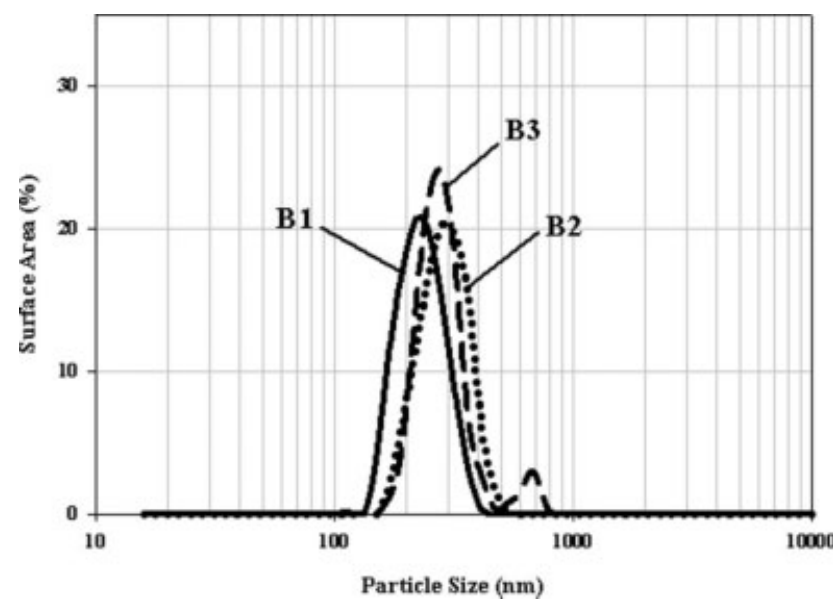

Figure 3 PSD of B1 (reference), B2 (without premix), and B3 (with premix). nucleation. Also, with the same emulsifier's dosage, B2 and B3 state the difference of applying the premix procedure.

Considering the critical micelle concentration (cmc) of $\mathrm{AL}$ at $1.1 \mathrm{~g} \mathrm{dm}^{-3}$, the monomodal type of

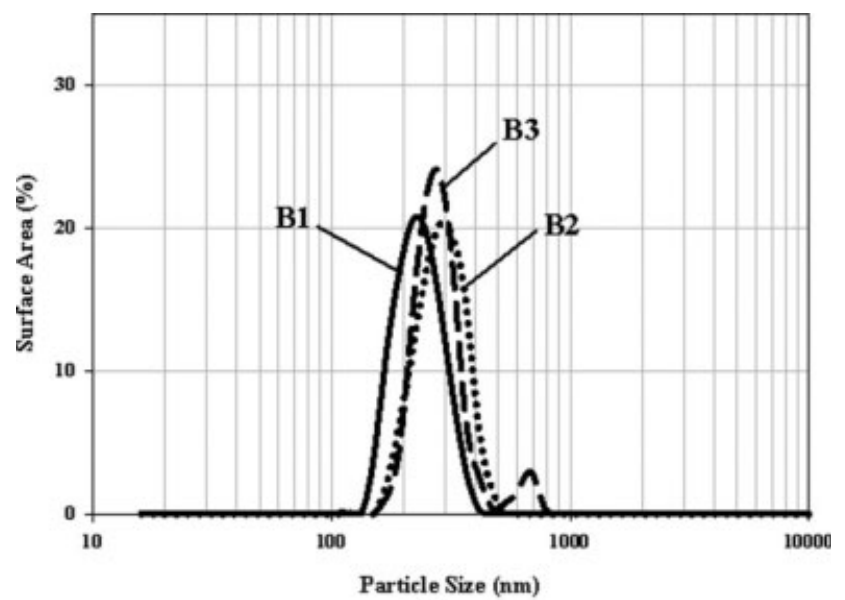

a)

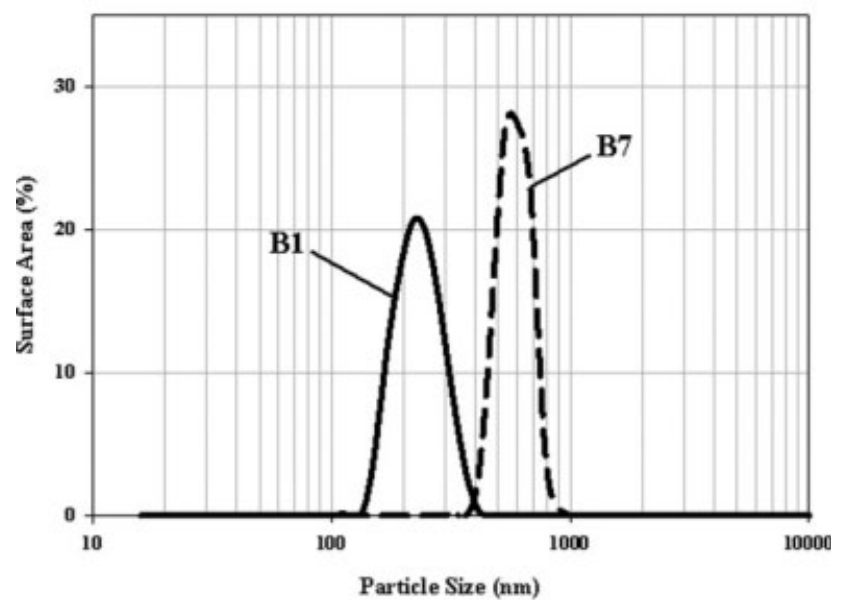

b)

Figure 4 Particle size distributions: (a) B4 (CA:AL = 3), $\mathrm{B} 5$ (CA:AL = 5), and B7 (CA:AL = 10); (b) B1 (reference) and B7. 
TABLE III

Batches with Different Coemulsifier:Emulsifier Ratios

\begin{tabular}{lcccc}
\hline & Unit $\backslash$ Batch & B8 & B9 & B10 \\
\hline VCM $_{\mathrm{t}}$ & $\mathrm{g}$ & 1100 & 1100 & 1100 \\
No. steps & - & 3 & 3 & 3 \\
AL (Step 1) & $\mathrm{g}$ & 1.68 & 1.12 & 0.56 \\
CA (Step 1) & $\mathrm{g}$ & 2.24 & 2.24 & 2.24 \\
CA:AL & - & 1.33 & 2.00 & 4.00 \\
Premix & - & Yes & Yes & Yes \\
$d_{50}$ & $\mathrm{~nm}$ & 234 & 241 & 626 \\
$d_{3,2}$ & $\mathrm{~nm}$ & 273 & 332 & 633 \\
$\left(d_{90}-d_{10}\right) / d_{50}$ & - & 1.246 & 1.737 & 0.402 \\
PSD & - & Bimodal & Bimodal & Monomodal \\
$N_{p} \times 10^{6}$ & $N_{p} \mathrm{~g}^{-1}$ & 67 & 37 & 5 \\
$A_{s}$ & $\mathrm{~m}^{2} \mathrm{~g}^{-1}$ & 15.8 & 13.0 & 6.8 \\
\hline
\end{tabular}

the PSD correlates directly with the predominant micellar nucleation type during the first step of the recipe. Comparing the results of $\mathrm{B} 1$ and $\mathrm{B} 2$, there is a slight difference between the obtained particle sizes from introducing the coemulsifier (CA). Nevertheless, with the same CA dosage, as soon as the premix procedure is applied (B3), there a clearly bimodal PSD (Fig. 3). Also, besides the sharp decrease in the number of particles $\left(N_{p}\right)$ from B1 to $\mathrm{B} 2$, in B3 there is a slight decrease in $N_{p}$ in accordance with the new class size in the distribution.

These results induce the fact that, some of the monomer droplets can be stabilized from the initial step of the reaction to produce a new class size. Because it is quite difficult to measure the size of initial monomer droplets and there was no kind of prehomogenization of the coemulsifier, the theories summarized by Ugelstad et al. ${ }^{16}$ can be applied to the phenomena, namely the monomer diffusion to the mixed micelles of surfactant and fatty alcohol (diffusional swelling) or the suggested mechanism of the fatty alcohol diffusion from the mixed micelles to the monomer droplets, leading to a spontaneous emulsification. Nevertheless, since the premix procedure was adopted, is seems more reliable that a diffusional swelling mechanism of the monomer took place before the start of the reaction.

Taking the advantages of the premix effect over the final PSD, in the performed batches B4-B7 the $\mathrm{CA}$ :AL ratio was progressively increased keeping the initial dosage of AL. The results from Table II show that the mean surface diameter $\left(d_{3,2}\right)$ increases with the $\mathrm{CA}$ dosage, indicating a lower $\mathrm{A}_{s}$ per mass of polymer and a lower $N_{p}$. Also, from B3, the PSD was kept bimodal, indicating a pronounced effect of the micellar nucleation of the anionic surfactant and a progressive effect of the nucleation in the monomer droplets promoted by the coemulsifier. This last effect takes a pronounced behavior on B7, leading to a new monomodal PSD type.
The marked differences on PSD are again stated in Figure 3(a,b), namely the evolution from B4, B5 until B7 and from the initial reference B1-B7. Again, only with very high ratio of CA:AL it was

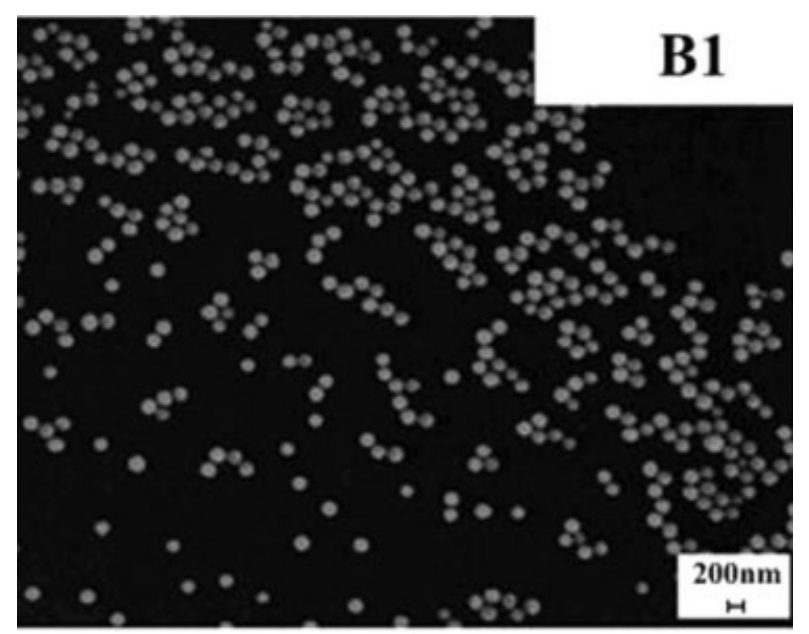

a)

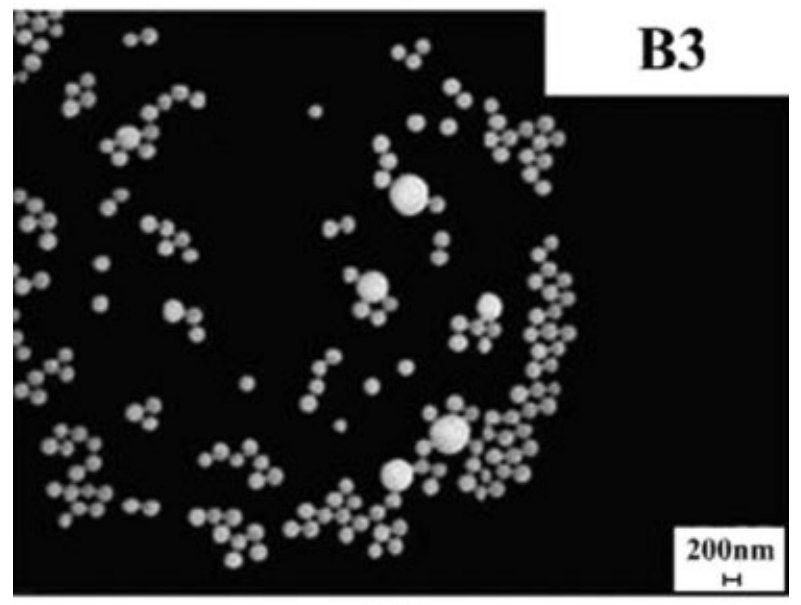

b)

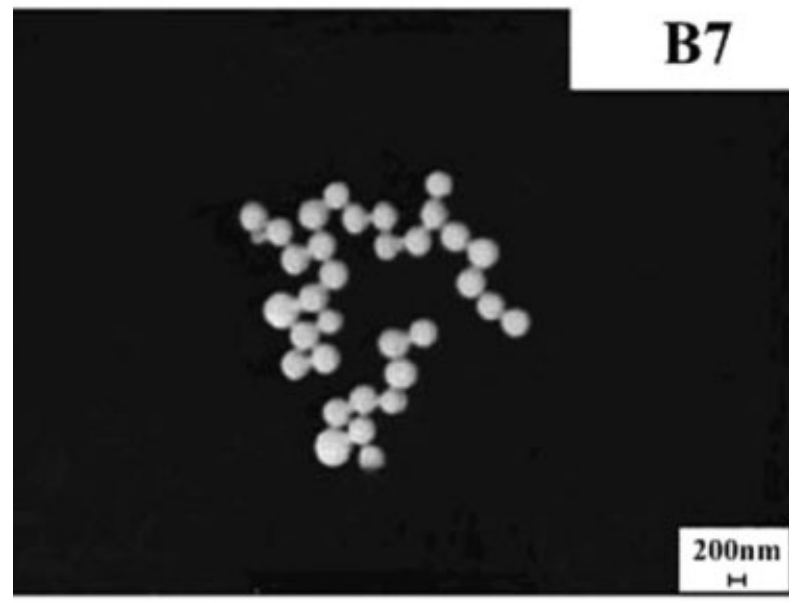

c)

Figure 5 Representative TEM micrographs of latex samples (magnification: $\times 7000$ ): (a) B1, (b) B3, and (c) B7. 


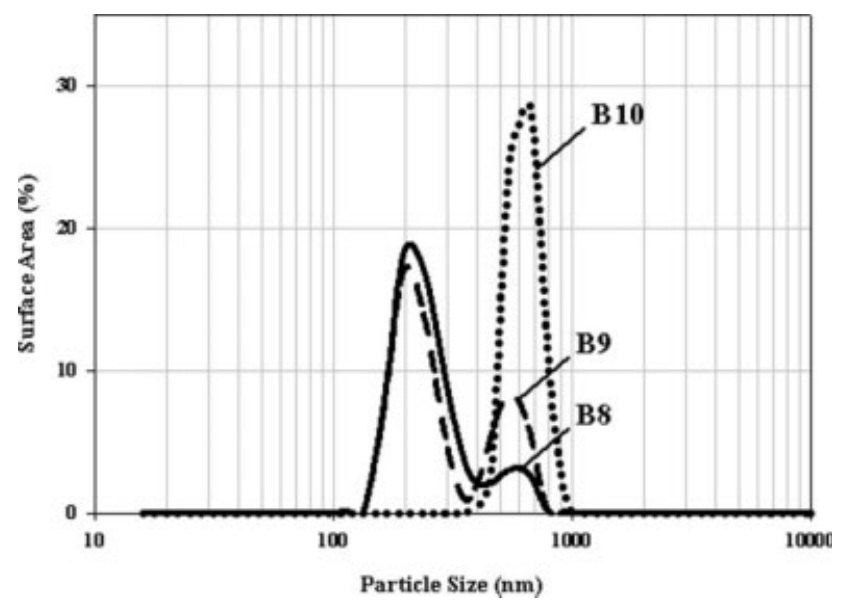

Figure 6 Particle size distributions: B8 (CA:AL = 1,33), B9 (CA:AL $=2)$, and B10 $(\mathrm{CA}: \mathrm{AL}=4)$.

possible to produce a new monomodal PSD with more than double of original mean size from the reference B1.

The TEM micrographs (Fig. 4) confirm the LDS technique, specially the new class size on B3 and the monomodal result of B7. Additionally, even with a mild premixture condition, the evidence that the monomer droplets can be stabilized with a combined emulsifier system. Moreover, the observed decreased on the number of particles, suggests a decrease of the micellar nucleation enhancing the initiation in the monomer phase.

\section{Effect of the anionic surfactant concentration}

Following the first results (B1-B7), the next study examined the surfactant concentration effect over the PSD at the end of the polymerization. That is, the increase on the ratio AL:CA, with a lower dosage of AL (Table III).

Comparing the results from the initial batches in Table II, the decrease of the anionic surfactant dos-

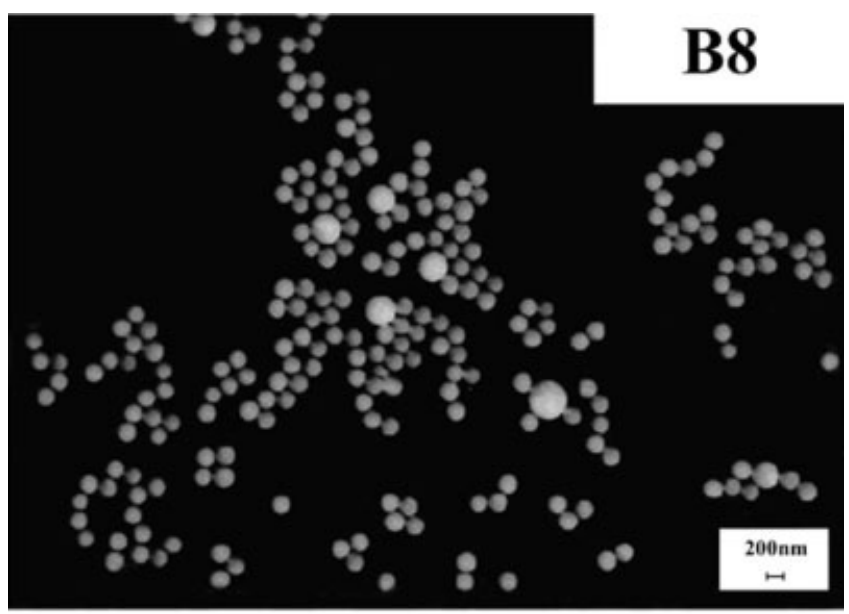

a)

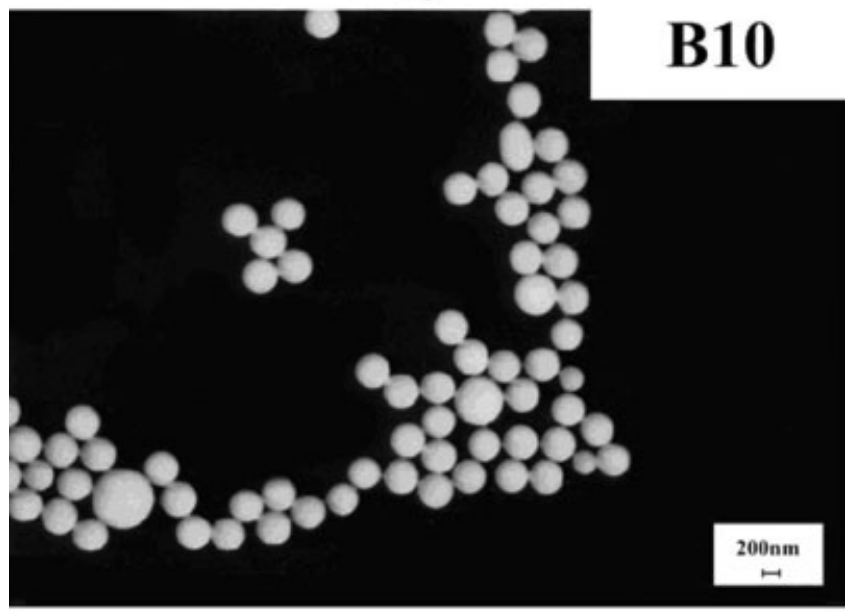

b)

Figure 7 Representative TEM micrographs of latex samples (magnification: $\times 7000$ ): (a) B8 and (b) B10.

age leads to a bimodal PSD keeping the same initial dosage of CA. Also, with the progressive increase on CA:AL ratio, the larger size class becomes more pronounced with a lower $N_{p}$ and the correspondent

TABLE IV

Batches with SLS or SOS and Different Coemulsifier: Emulsifier Ratios

\begin{tabular}{|c|c|c|c|c|c|c|c|}
\hline & unit $\backslash$ batch & B11 & B12 & B13 & B14 & B15 & B16 \\
\hline $\mathrm{VCM}_{\mathrm{t}}$ & $\mathrm{g}$ & 1100 & 1100 & 1100 & 1100 & 1100 & 1100 \\
\hline No. steps & - & 3 & 3 & 3 & 3 & 3 & 3 \\
\hline SLS (Step 1) & $\mathrm{g}$ & 2.24 & 2.24 & 2.24 & 2.24 & 2.24 & 2.24 \\
\hline SOS (Step 1) & $\mathrm{g}$ & - & - & - & 2.24 & 1.12 & 0.56 \\
\hline CA (Step 1) & $\mathrm{g}$ & - & 2.24 & 2.24 & - & 2.24 & 2.24 \\
\hline CA:SLS (SOS) & - & - & 2 & 4 & - & 2 & 4 \\
\hline Premix & - & - & Yes & Yes & - & Yes & Yes \\
\hline$d_{50}$ & $\mathrm{~nm}$ & 103 & 110 & 178 & 614 & 658 & 736 \\
\hline$d_{3,2}$ & $\mathrm{~nm}$ & 109 & 156 & 202 & 623 & 662 & 750 \\
\hline$\left(d_{90}-d_{10}\right) / d_{50}$ & - & 0.833 & 1.834 & 1.449 & 0.390 & 0.384 & 0.399 \\
\hline PSD & - & Monomodal & Bimodal & Monomodal & Monomodal & Monomodal & Monomodal \\
\hline$N_{p} \times 10^{6}$ & $N_{p} g^{-1}$ & 1059 & 361 & 166 & 5 & 4 & 3 \\
\hline$A_{\mathrm{s}}$ & $\mathrm{m}^{2} \mathrm{~g}^{-1}$ & 39.5 & 27.6 & 21.3 & 6.9 & 6.5 & 5.7 \\
\hline
\end{tabular}




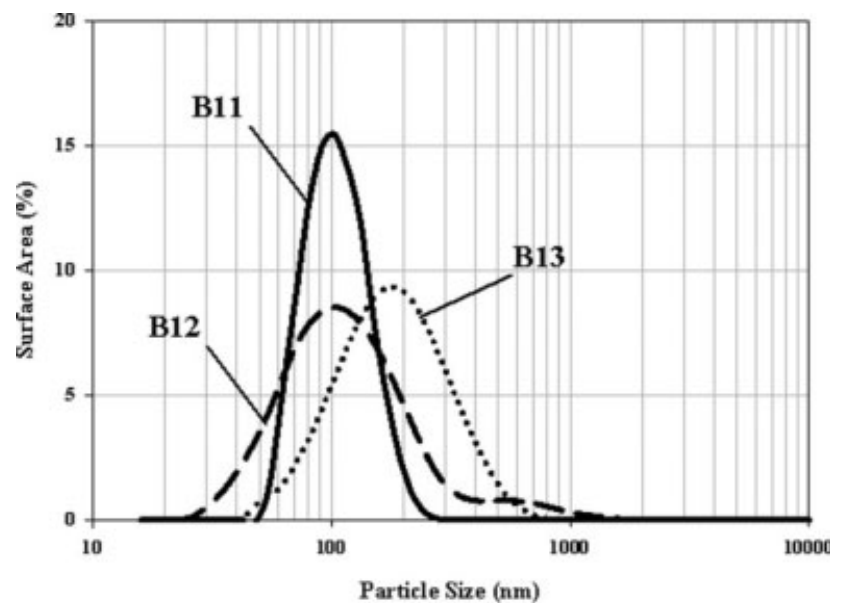

a)

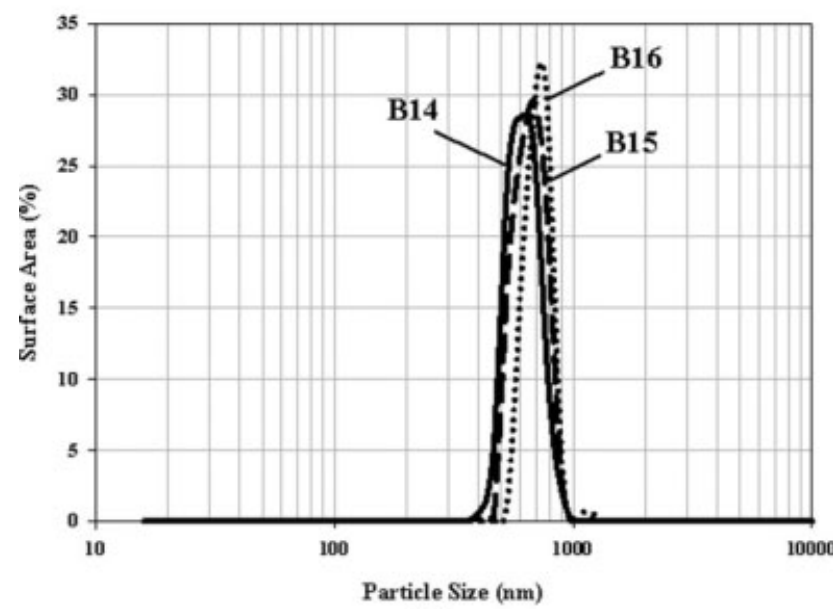

b)

Figure 8 Particle size distributions: (a) B11 (SLS reference), B12 (CA:SLS = 2), and B13 (CA:SLS = 4); (b) B14 (SOS reference), B15 (CA:SOS = 2), and B16 (CA:SOS =4).

increase on $d_{3,2}$ and span, translating the broadening of the size distribution.

The decrease of the AL dosage enhances the coemulsifier effect by decreasing the micellar nucleation mechanism (Fig. 5). Moreover, for the same PSD type in Table II, the CA dosage can be optimized just by a correct ratio with AL. Adding, with a minimum quantity of $\mathrm{AL}$, keeping the previous emulsification procedure of CA (B10), the micellar nucleation is inhibited producing a single and narrower PSD type at end of the three reaction steps (Fig. 6).

\section{Effect of the anionic surfactant type}

Considering the impact of the initial dosage of the anionic surfactant, a new set of four batches was performed to investigate the effect of the type of surfactant over the final PSD. That is, by applying different anionic emulsifiers with different hydrophilic and hydrophobic groups, the behavior of the particle size can be completely distinct from the original. In Table IV, the application of SLS, with a very low cmc $\left(0.38 \mathrm{~g} \mathrm{dm}^{-3}\right)$, promotes the micellar effect preventing higher particle sizes. Even with a high quantity of CA (B12 and B13), the PSD becomes broader, but the mean size does not change in the same magnitude as observed with AL (B10) (Fig. 7a).

On the other hand, the application of the SOS with a cmc of $16 \mathrm{~g} \mathrm{dm}^{-3}$, produces a very small $N_{p}$,

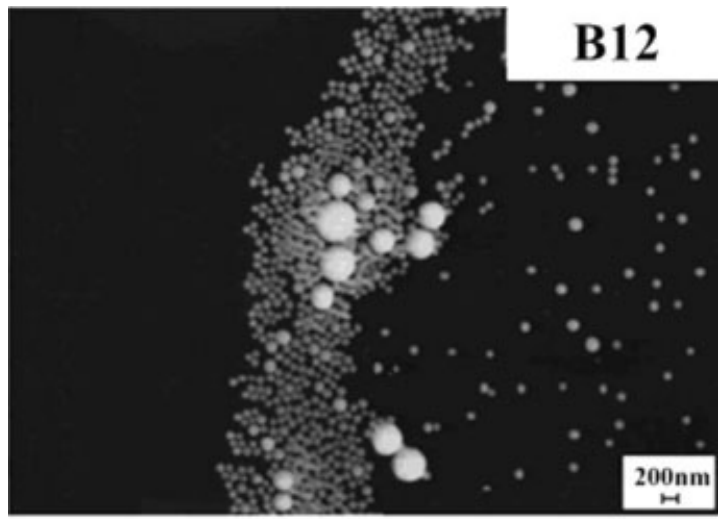

a)

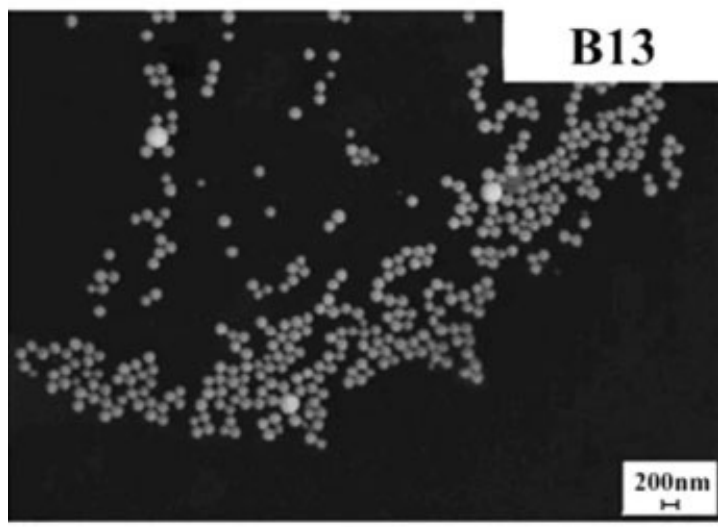

b)

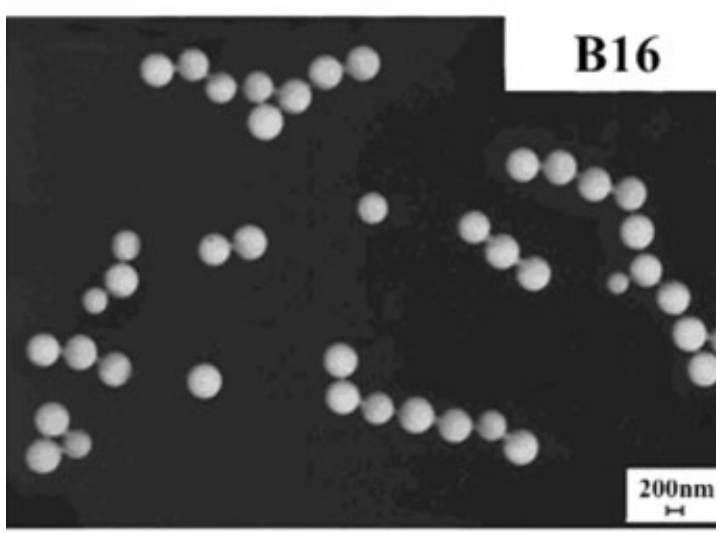

c)

Figure 9 Representative TEM micrographs of latex samples (magnification: $\times 7000$ ): (a) B12, (b) B13, and (c) B16. 
with monomodal type PSD even with the mixed CA procedure (Fig. $7 \mathrm{~b}$ ). Considering that the initial aqueous concentration of SOS is clearly below the $\mathrm{cmc}$, the predominant homogenous nucleation mechanism it is not affected by the CA introduction. That is, from Table IV, it is possible to conclude that there is only a small difference between B14 and B16, which induces the fact that the nucleation in the monomer droplets is being slowly introduced in the system replacing the homogeneous nucleation type.

The micellar nucleation in the aqueous phase seems to increase when applied a surfactant with a lower cmc [Fig. 8(a,b)]. Thus, for SLS the size of the final particles is kept small with a slight broader effect on the distribution. However, with AL the PSD can have a fraction of larger particles or even, for high coemulsifier dosages, a monomodal narrower distribution (Fig. 6b). In the absence of micelles, as in the case of the SOS, there is only a slight effect of the coemulsifier by enhancing the droplets nucleation (Fig. 9c).

\section{CONCLUSIONS}

PSD of latex particles is a key parameter in the emulsion polymerization of $\mathrm{VCM}$, since it plays an important role in affecting both latex and final powder properties. The results shown in this study prove that it is possible to have significant differences in the final PSD by changing the ratio of the coemulsifier over the anionic surfactant concentration. Depending on the required final properties, different PSD types can be produced with a correct optimization of the surfactant's ratio. Moreover, comparing the conventional emulsion polymerization with the applied premix technique, the selected anionic surfactant plays a fundamental role on the nucleation mechanism, since the micellar type can be predominant or completely inhibited, with the correspondent differences on having final small or large polymer particles, with a broader or narrower PSD type. Thus, the practical significance of this work can be well established by the control of the mean particle size and size distribution of the emulsion PVC polymers for different rheological properties of the final product.

\section{NOMENCLATURE}

\begin{tabular}{|c|c|}
\hline AL & Ammonium laurate \\
\hline$A_{s}$ & $\begin{array}{l}\text { Specific surface area }\left(\mathrm{m}^{2} \mathrm{~g}^{-1} \text { of }\right. \\
\text { polymer })\end{array}$ \\
\hline B1-B16 & Batch reference \\
\hline CA & Cetyl alcohol \\
\hline $\mathrm{Cmc}$ & $\begin{array}{l}\text { Critical micellar concentration (g } \\
\left(\mathrm{dm}^{-3}\right)\end{array}$ \\
\hline 10 & $\begin{array}{l}\text { Particle diameter corresponding to the } \\
10 \% \text { cumulative percentage }(\mathrm{nm})\end{array}$ \\
\hline
\end{tabular}

$d_{3,2}$

$d_{50}$

$d_{90}$

$\left(d_{90}-d_{10}\right) /$ day $_{50}$

$d_{i}$

LDS

$n_{i}$

$N_{p}$

PVC

PSD

SLS

SOS

TEM

$T_{\text {poly }}$

VCM

\section{Greek characters}

$\rho_{p}$

$$
\begin{gathered}
\text { Density of poly(vinyl chloride) }(\mathrm{kg} \\
\left.\mathrm{m}^{-3}\right)
\end{gathered}
$$

\section{References}

1. Nakajima, N.; Harrel, E. R. J Colloid Interface Sci 2001, 238, 105.

2. Saethre, B.; Preben, C. M.; Ugelstad, J. Polym Sci Part A: Polym Chem 1995, 33, 2951.

3. Ugelstad, J.; Mørk, P. C.; Berge, A. In Vinyl Chloride Polymerization; El-Aasser, M. S.; Lovell, P.A., Eds.; Wiley: New York, 1997; pp 590-618.

4. Cadries, P.; Zekol, H. U.S. Patent5, 300, 551, 1994.

5. Sarvetnick, H. A.; Plastisols and Organosols; Van Nostrand Reinhold Company: New York, 1972.

6. Ugelstad, J.; El-Aasser, M. S.; Vanderhoff, J. W. J Polym Sci Polym Lett 1973, 11, 503.

7. Azad, A.; Fitch, R. M.; Ugelstad, J. Emulsification and emulsion polymerization using cationic surfactants and long chain fatty alcohols; ACS Symposium Series 24:1, 1976.

8. Hansen, F. K.; Ugelstad, J. Polym Sci: Polym Chem Ed 1978, 16, 1953.

9. Higuchi, W. I.; Misra, J. Pharm Sci 1962, 51, 459.

10. Ugelstad, J.; Mørk, P. C.; Kaggerud, K. H.; Ellingsen, T.; Berge, A. Adv Colloid Interf Sci 1980, 13, 101.

11. Ugelstad, J.; Berge, A.; Ellingsen, T.; Schimd, R.; Nilsen, N.; Mørk, P. C.; Stenstad, P.; Hornes, E.; Olsvik, Ø. Prog Polym Sci 1992, 17, 87.

12. Alsopp, M. W.; Vianello, G. In Vinyl Chloride Polymers, Encyclopedia of Polymer Science and Technology, Vol. 8. Wiley: New Jersey, E.U.A, 2003; pp 437-476

13. Elvers, B.; Hawkins, S.; Schulz, G., Eds. Ulmann's Encyclopedia of Industrial Chemistry, 5th ed.; Germany, 1992; Vol. A21, pp 373-390.

14. Garton, A.; George, M. H. J Polym Sci: Polym Chem Ed 1974, $12,2779$.

15. Collins, E. A.; Daniels, C. A.; Witenhafer, D. E.; In Physical Constants of Poly(vinyl chloride), 4th ed.; Brandrup, J.; Immergut, E. H.; Grulke, E. A., Eds.; Wiley: New York, 2003; Vol. 67-74.

16. Ugelstad, J.; Mørk, P. C.; Hansen, F. K.; Kaggerud, K. H.; Ellingsen, T. Pure Appl Chem 1981, 53, 323. 